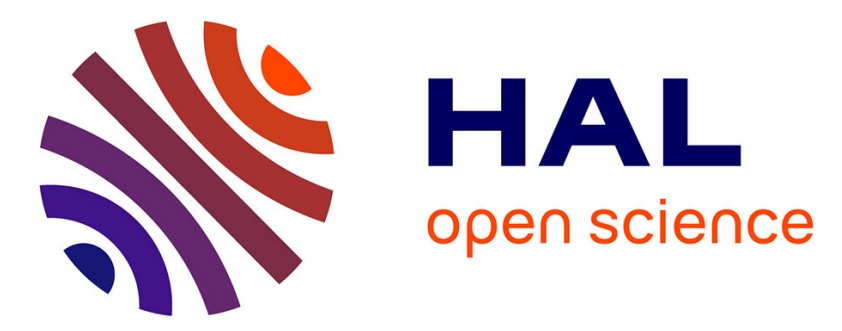

\title{
Dedicated oven for optical resonator heating process
}

Patrice Salzenstein, David Bassir, Mikhail Zarubin

\section{To cite this version:}

Patrice Salzenstein, David Bassir, Mikhail Zarubin. Dedicated oven for optical resonator heating process. SPIE/COS Photonics Asia, Oct 2018, Beijing, China. 10.1117/12.2500664 . hal-02131417

\section{HAL Id: hal-02131417 https://hal.science/hal-02131417}

Submitted on 10 Aug 2021

HAL is a multi-disciplinary open access archive for the deposit and dissemination of scientific research documents, whether they are published or not. The documents may come from teaching and research institutions in France or abroad, or from public or private research centers.
L'archive ouverte pluridisciplinaire HAL, est destinée au dépôt et à la diffusion de documents scientifiques de niveau recherche, publiés ou non, émanant des établissements d'enseignement et de recherche français ou étrangers, des laboratoires publics ou privés.

\section{(c)(1)}

Distributed under a Creative Commons Attribution| 4.0 International License 


\title{
Dedicated oven for optical resonator heating process
}

\author{
Patrice Salzenstein ${ }^{1 *}$, David Bassir ${ }^{2,3}$ and Mikhail Zarubin ${ }^{4}$ \\ ${ }^{1}$ CNRS, UBFC, FEMTO-ST institute, 15B avenue des Montboucons, F25030 Besançon Cedex, FRANCE \\ ${ }^{2}$ Université Technlogique de Belfort Montbéliard (UTBM), F90010 Belfort, FRANCE \\ ${ }^{3}$ CMLA, ENS Cachan, CNRS, Université Paris-Saclay, F94235 Cachan, FRANCE \\ ${ }^{4}$ Special Technological Center, ul. Gzatskaia, dom 21, Kor. 2, Saint-Petersburg, RUSSIA \\ E-mail: patrice.salzenstein@femto-st.fr, david.bassir@cmla.ens-cachan.fr,mozgzm@gmail.com \\ * Corresponding author and presenting author
}

\begin{abstract}
Optical resonators are useful to achieve optoelectronics oscillators or frequency combs. High-Q factor resonators for photonics applications are obtained by polishing. To gain in terms of performance, a way is to perform a controlled annealing process to improve the roughness of resonator's surface down to the nanometer scale. We present the setup and explain it.
\end{abstract}

\section{KEYWORDS}

Oven, thermal annealing, nichrome, resonator, CFD fluid module, ANSYS

\section{INTRODUCTION}

In order to have stable frequency signals, it is possible to choose frequencies in the radio frequency domain. Quartz performances have long been known and reproducible [1 - 3]. In recent years, however, there has been no significant progress in terms of stability of Frequency or phase noise [4]. For more than twenty years, efforts have been made to make optoelectronic oscillators [5]. In our laboratory, we have made delay line-based optoelectronic oscillators and crystal resonators [6 - 9]. These oscillators can be characterized with special benches $[10-12]$. They perform well in terms of quality factors.

Let us return here to the question of how to improve the quality factor of ultra-stable crystalline resonators. There is a two-step manufacturing process [13]. But we see that it is necessary to introduce an annealing stage. In fact, the outer surface of the optical resonator is subjected to numerous stresses during polishing. We must ensure that the state of constraint is relaxed. This will ensure that the roughness will be as low as possible. For the best resonators, aim for a roughness of the order of the nanometer.

For this purpose, we have developed a special annealing oven. The oven operates from room temperature up to almost $700^{\circ} \mathrm{C}$. Of course, we could have used a commercial oven, but we were guided by the need for a specific oven. In fact, it is necessary to be able to heat a resonator that is relatively small by controlling the temperature as much as possible. An oven cavity that is too large is too difficult to control. No need to have a big oven as the diameter of the resonator is only about 5 to $6 \mathrm{~mm}$. Free spectral range in X-band dictates the choice of this diameter.

In the following section, we will therefore look at the main elements of the furnace. Then we will look at the simulations. 


\section{WHAT ARE THE TIPS FOR MAKING THE ANNEALING OVEN?}

The main lines of the oven principle that we have achieved are given in the following references [14,15]. This reference can be consulted for furnace electronics [16]. The important thing with the electronic control of the current injected into the NiChrome wires is to control the rise time. A too fast ramp would almost inevitably damage the surface of the resonator to be annealed. On the contrary, the temperature rise ramp must be soft enough to allow relaxation of all kinds of stresses and to ensure an improvement in the quality factor of the resonators. Wires for heating are in Nichrome which is made of nickel, chromium and a bit of iron. Thermal expansion is $14 x E-6 \mathrm{~m} / \mathrm{m} /{ }^{\circ} \mathrm{C}$. Its Specific heat capacity is $450 \mathrm{~J} / \mathrm{kg}^{\circ} \mathrm{C}$. It is recalled that the most important was the idea of using NiChrome threads intertwined in clay. It may be surprising that Clay is used. But this material has properties that are favorable for this type of use. On the one hand, the clay is easy to model to give it the shape to accommodate the foot of the resonator. On the other hand, Clay has self-repairing properties. It is therefore better able to withstand successive annealing cycles, although it is necessary to replace the supports after several cycles if the rise or fall in temperature has been too rapid, causing a heat shock. Finally, the other idea was to surround this clay support with Basalt Fiber [17]. The type of the basalt is "BAS NW 10MM" manufactured in Wevegem in Belgium by Basaltex SA. "NW" means No woven ". Non woven mats are made of $100 \%$ bulk continuous filament (BCF) fibers with high thermal insulation properties, high thermal and chemical resistances. Characteristics of sensors such as platinum resistance thermometers, thermistors and thermocouples can be found in reference [18]. A variety of techniques is reminded in reference [19]. The shape of the support is made for resonators to be in a miniature for a better thermal control. The principle of this annealing is to send a 1 to 6 A DC electric current inside the alloy.

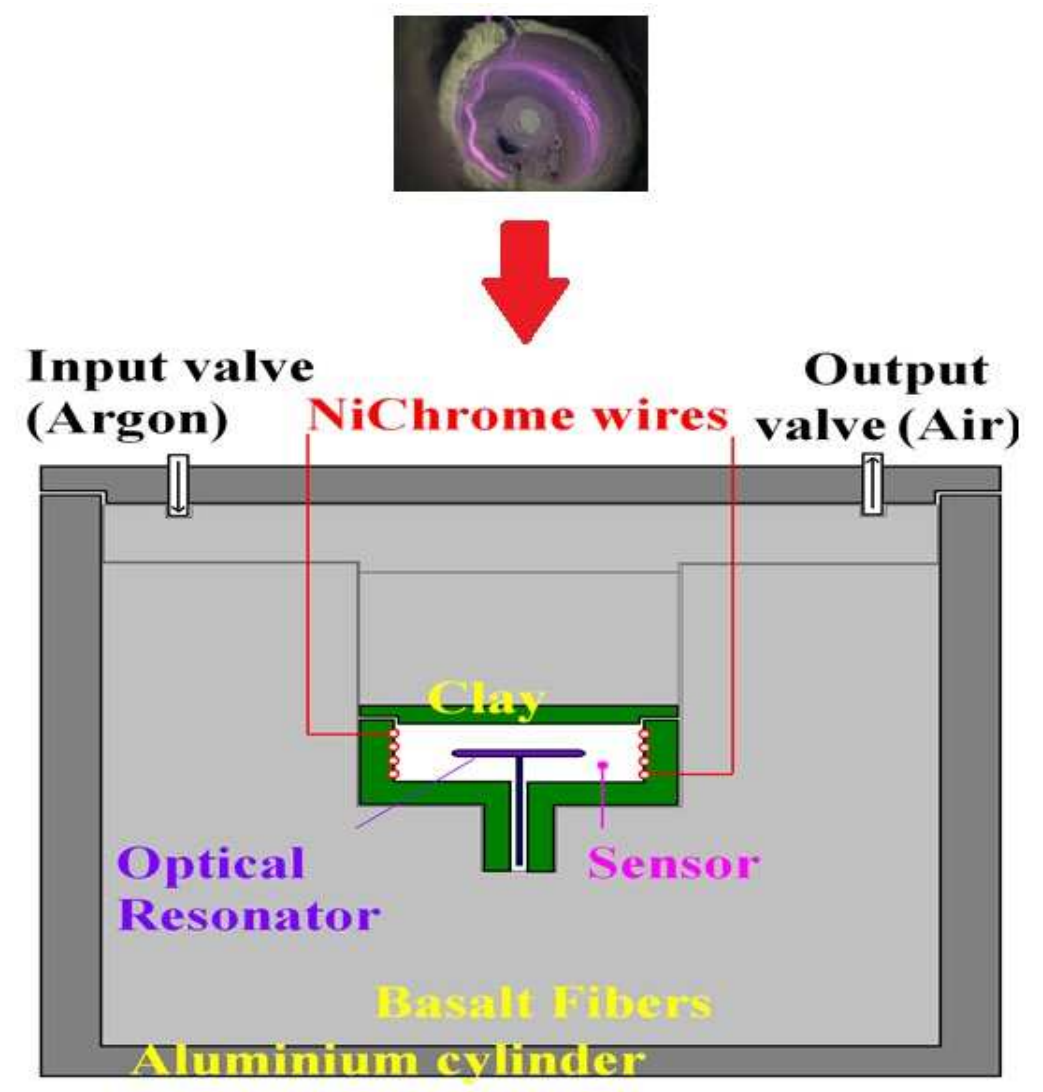

Fig. 1. structure of the oven 


\section{FINITE ELEMENT SIMULATION}

To understand the residual stresses inside the resonator, we have simulated the heating process in the oven using the finite element code ANSYS $\odot$ and CFD fluid module [20]. The resonator is in the middle of a cylinder with uniform distribution of the temperature all around the part. For this simulation, we neglect the dissipation through the support that link the base and the resonator. Due to the symmetry along the two axis, only $1 / 4$ is used for the thermal analysis. For better accuracy, we have used 20840 nodes and 77685 (3D) finite elements within ANSYS Workbench. It is shown on Figure 2.

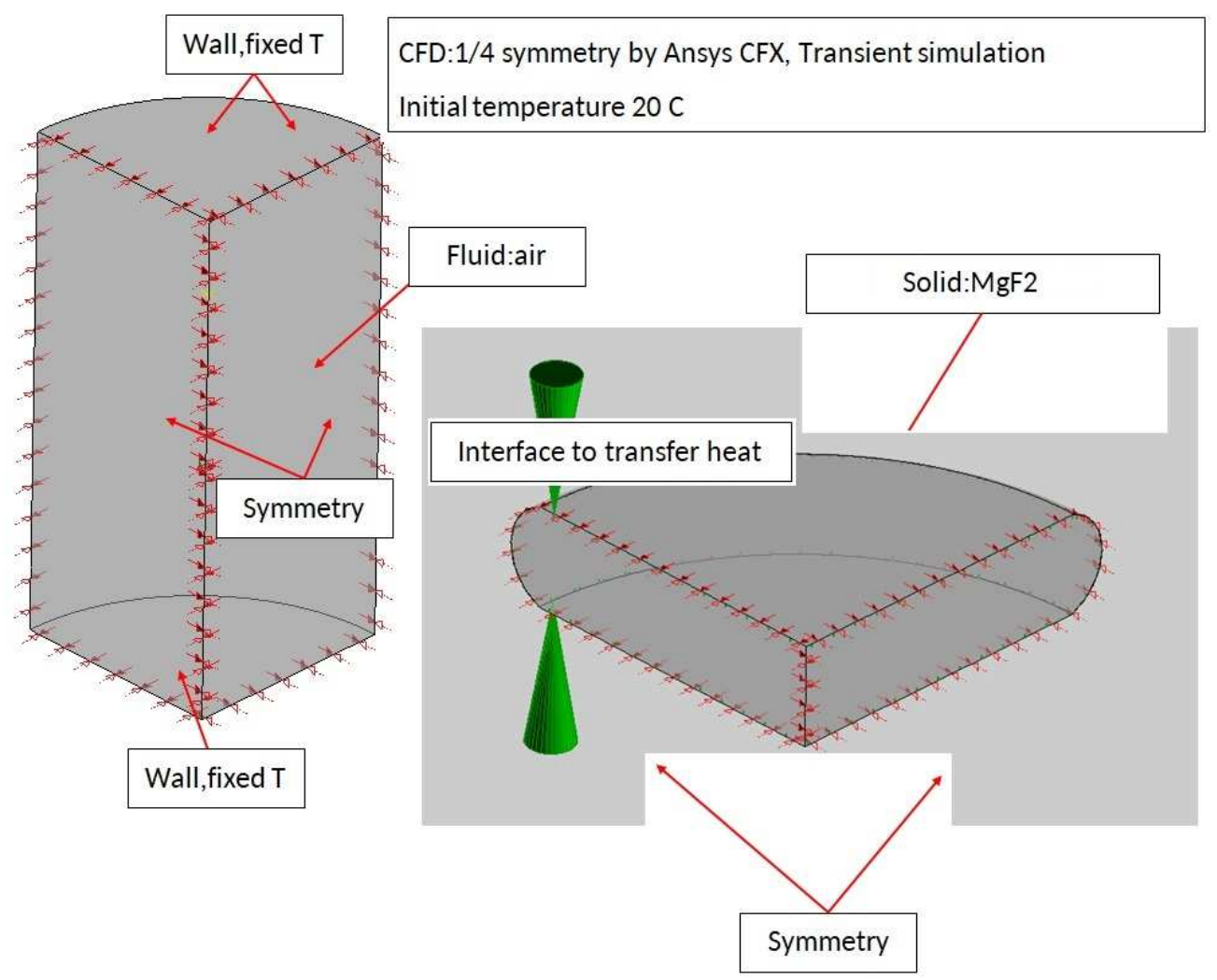

Fig. 2. Due to the symmetry, finite element analysis is reduced to $1 / 4$ of the structure (initial temperature is set to 20 degree)

In the following figures 3 and 4, we can see the thermal diffusion inside the resonator at different times (at $\mathrm{t}=10 \mathrm{~s}, 20 \mathrm{~s}, 50 \mathrm{~s}$ and 100s) for three input temperatures. We focus on these two main temperatures (100 and $700^{\circ} \mathrm{C}$ ) because it has been proven that $\mathrm{MgF} 2$ resonator start relaxing at this rang. We can notice the speed of the diffusion along the disk increase with the increase of temperature. The curved shape at the edge of resonator cumulate more thermal energy at the first stage, and relaxed during heating. This process allowed us to decrease the internal residual stresses related. 


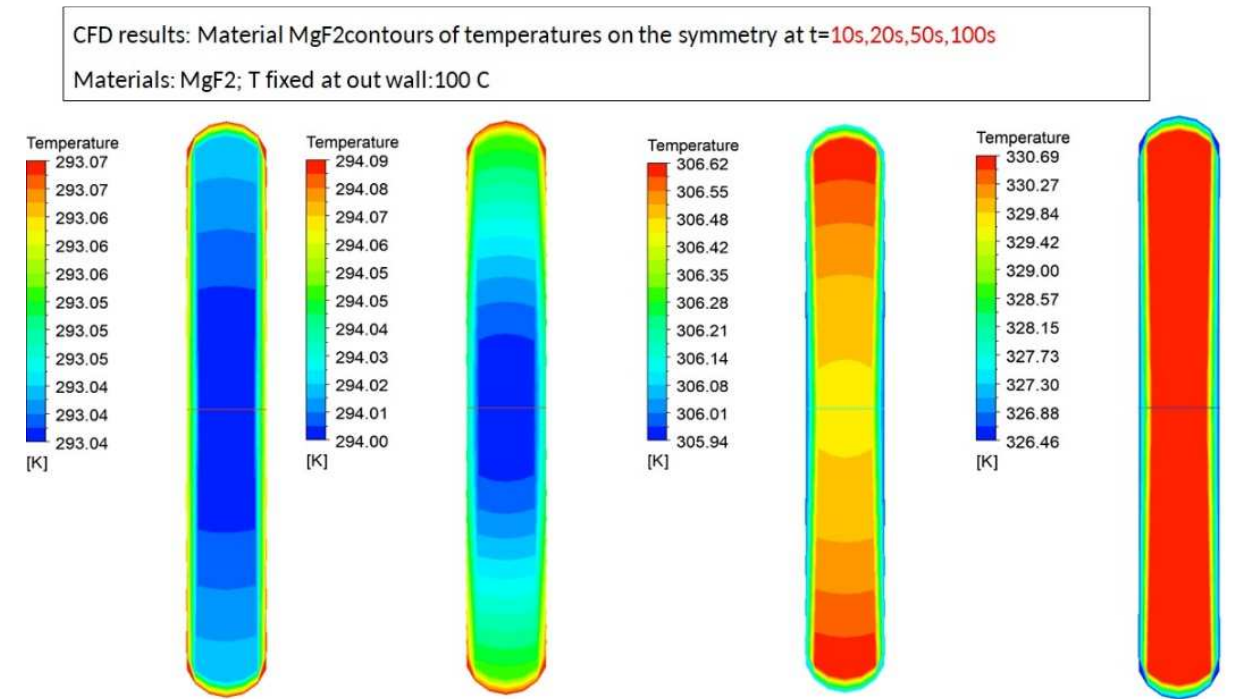

Fig. 3. FE simulation of the thermal diffusion for $\mathrm{MgF}_{2}$ resonator at $\mathrm{t}=10 \mathrm{~s}, 20 \mathrm{~s}, 50 \mathrm{~s}, 100 \mathrm{~s}$ and the temperature $\mathrm{T}$ is fixed at out wall at $100{ }^{\circ} \mathrm{C}$.

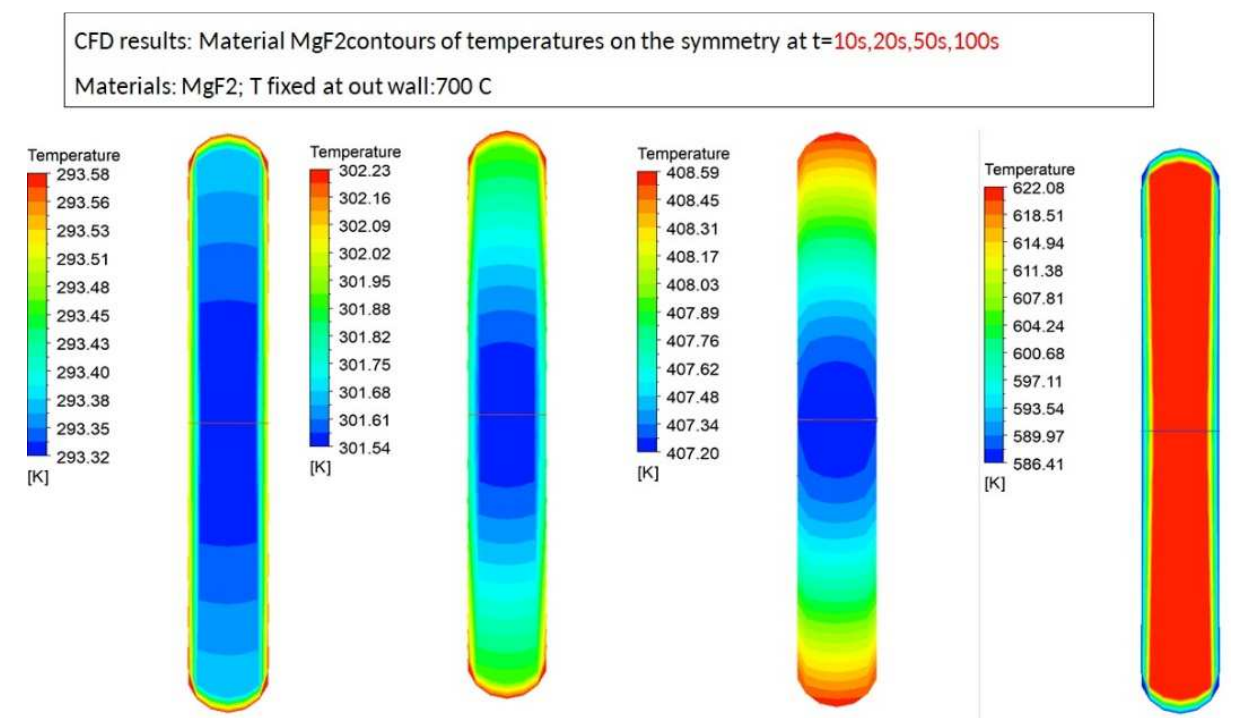

Fig. 4. FE simulation of the thermal diffusion for $\mathrm{MgF}_{2}$ resonator at $\mathrm{t}=10 \mathrm{~s}, 20 \mathrm{~s}, 50 \mathrm{~s}, 100 \mathrm{~s}$ and the temperature $\mathrm{T}$ is fixed at out wall at $700{ }^{\circ} \mathrm{C}$. 


\section{CONCLUSION}

In this paper, we provide the main element of the oven and of the holder for resonators heating process. nichrome resistant alloy wires and special chopped basalt fibers for thermal isolation are essential elements or the realized oven. In this paper, we have also performed a finite element simulation of the heating using ANSYS code to describe the thermal diffusion within the resonator at different times and temperature. It is clear that the process described below allows decreasing the internal residual stresses. However, further investigation is running to measure the roughness before and after the heating process using non-indentation technics and X-ray imaging. This should help us to better quality our resonator.

\section{REFERENCES}

[1] Kuna A., Cermak J., Sojdr L., Salzenstein P., Lefebvre F., "Lowest Flicker-Frequency Floor Measured on BVA Oscillators," IEEE Transactions on UFFC 57(3), 548-551 (2010).

[2] Salzenstein P., Kuna A., Sojdr L., Sthal F., Cholley N. and Lefebvre F., "Frequency stability measurements of ultra-stable BVA resonators and oscillators," Electronics Letters 46(10), 686-688 (2010).

[3] Sthal F., Imbaud J., Vacheret X., Salzenstein P., Cibiel G. and Galliou S., "Computation method for the short-term stability of quartz crystal resonators obtained from passive phase noise measures," IEEE Transactions on UFFC 60(7), 1530-1532 (2013).

[4] Salzenstein P., Kuna A., Sojdr L. and Chauvin J., "Significant step in ultra high stability quartz crystal oscillators," Electronics Letters 46(21), 1433-1434, (2010).

[5] Savchenkov A. A., Matsko A. B., Ilchenko V. S., Yu N., Maleki L., "Whispering-gallery-mode resonators as frequency references. II. Stabilization," J. Opt. Soc. Am. B 24(12), 2988-2997 (2007).

[6] Salzenstein P., Mortier M., Sérier-Brault H., Henriet R., Coillet A., Chembo Y. K., Rasoloniaina A., Dumeige Y., Féron P., "Coupling of high quality factor optical resonators," Physica Scripta T157, 014024 (2013).

[7] Salzenstein P., Voloshinov V. B. and Trushin A. S., "Investigation in acousto-optic laser stabilization for crystal resonator based optoelectronic oscillators," Optical Engineering 52(2), 024603 (2013).

[8] Henriet, R., Salzenstein, P., Ristic, D., Coillet, A., Mortier, M., Rasoloniaina, A., Saleh, K., Cibiel, G., Dumeige, Y., Ferrari, M., Chembo, Y. K., Llopis, O., Féron, P., "High quality factor optical resonators," Physica Scripta T162, 014032 (2014).

[9] Salzenstein P., "An example of design, optimization, stabilization and noise performances of resonator based optoelectronic oscillators," Int. J. for Sim. and Mult. Design Optimization 10, A2 (2019).

[10] Salzenstein P., Pavlyuchenko E., Hmima A., Cholley N., Zarubin M., Galliou S., Chembo Y. K. and Larger L., "Estimation of the uncertainty for a phase noise optoelectronic metrology system," Physica Scripta T149, 014025 (2012).

[11] Salzenstein P., Pavlyuchenko E., "Determination of the uncertainty for phase noise delivered by an optoelectronic based system," Proc. SPIE 8772, 877217 (2013). 
[12] Salzenstein P., Wu T. Y., "Uncertainty analysis for a phase-detector based phase noise measurement system," Measurement 85, 118-123 (2016).

[13] Salzenstein P., Coillet A., Henriet H., Larger L., Yanne K. Chembo Y. K., " Experimental study of a crystalline-resonator based optoelectronic oscillator", Proc. SPIE 8772, 87720O, (2013).

[14] Salzenstein P., Diallo S., Zarubin M., "Electrically driven thermal annealing set-up dedicated to high quality factor optical resonator fabrication," Journal of Power Technologies 98(2), 198-201 (2018).

[15] Salzenstein P., Bassir, D., Hao, Y., Zarubin M., "Dedicated oven for optical resonator heating process," Proc. SPIE 10814, 1081417 (2018).

[16] Salzenstein P., Zarubin M., "Electronics improvements for optical resonators fabrication," Proc. SPIE 10814, 1081418 (2018).

[17] Sim J., Park C., Moon D. Y., "Characteristics of basalt fiber as a strengthening material for concrete structures," Composites Part B: Engineering 36, 504-512 (2005).

[18] Bentley J. P., "Temperature sensor characteristics and measurement system design," Journal of Physics E: Scientific Instruments 17(6), 430 (1984).

[19] Childs P. R. N., Greenwood J. R., Long C. A., "Review of temperature measurement," Review of Scientific Instruments 71, 2959 (2000).

[20] Gao T., Zhang W. H., Zhu J. H., Xu Y. J., Bassir D. H., "Topology optimization of heat conduction problem involving design-dependent heat load effect," Finite Elements in Analysis and Design 44(14), 805813 , (2008). 